\title{
Dynamic Learning Platform for Dynamic EFL Learners: A New Journey to Navigate Effective E-Learning Program for English Education at the University Level
}

\author{
Murshida Parvin ${ }^{1}$ \\ ${ }^{1}$ Department of English, Faculty of Languages, Najran University, Saudi Arabia \\ Correspondence: Murshida Parvin, Department of English, Faculty of Languages, Najran University, Saudi \\ Arabia. E-mail: murshida001@yahoo.com
}

Received: December 21, 2019 Accepted: January 20, 2020 Online Published: February 5, 2020

doi:10.5539/ijel.v10n2p170 URL: https://doi.org/10.5539/ijel.v10n2p170

\begin{abstract}
With the innovation of technology, the nature of learning and teaching English as a Foreign Language (EFL) has been changed, and instead of traditional learning and teaching, e-learning has emerged as a new way to meet the demands of the 'iGeneration' who can easily roam around the knowledge domain just with a smartphone at anytime from anywhere. This research aims to find out the challenges of e-language learning that will help establish a more sophisticated Virtual Learning Environment (VLE) by implementing the latest version of the Learning Management System (LMS). E-learning is 'constructive learning' or 'self-regulated learning' where the learners work as 'knowledge generators' and teachers as 'facilitators' and so, the learning should be accomplished in a platform that ensures interaction, communication, and collaboration. This research will be provocative of establishing such an environment where online foreign language learners and instructors can adapt easily to the new pedagogical approach to learning for successfully attaining the target learning outcomes. A survey was conducted at the department of English, Najran University (Girls' section), the Kingdom of Saudi Arabia, and the findings show the necessity of improving teachers' efficiency in selecting e-learning tools to design learning materials and contents of the course considering cultural context and the modern-day learners' capacity as well as the goal. It also discusses various implications regarding the need for e-language learners' skill development that vigorously affects the learning process. The paper finally recommends some possible steps that can be adopted by a university for the successful implementation of e-learning to widen the realm of knowledge for the learners of English as Foreign Language (EFL).
\end{abstract}

Keywords: 21st-century language learners and teachers, e-language learning, e-learning challenges, participatory culture

\section{Introduction}

The magical touch of technology has converted this world into a 'global village' in the real sense of the term; as a result, today's generation of learners has become dynamic and is considered the 'whole child'. The 'whole child' refers to the concept of 'oneness' as they are living in a strong networking era. Considering this revolutionary behavioural and attitudinal changes among the new generation, more research is being conducted for discovering a dynamic learning environment in order to bring all the EFL learners under one knowledge domain where they can merge through interaction and thus attain both formal and informal learning. Experts advocate for E-learning Platform (ELP) as the only choice to achieve the target learning outcomes for the whole child living in this 'knowledge society' that is creative and dynamic (Hargreaves, 2003). The target learning outcomes for the second language learners can be examined with reference to $\mathbf{4 C}$ 's - creativity, collaboration, communication, and critical thinking. Many researchers opine that these are the four newly set learning outcomes and they can fully be achieved by developing modern-day language learners' anatomy to enable them to work in four steps: organizing their own learning, forming their own judgements, deciding on a point of view, and defending their own position in an area of knowledge set and designed by the teachers who play the role of the designer as well as the guide. Here, the main important thing is to increase learners' engagement so that all the learners can improve their four skills- reading, writing, listening, and speaking. 


\subsection{Purpose of the Study}

To meet better 21st-century language learners' needs and expectations various researches have been done on different pedagogies and finally, the studies advocate for creating such a virtual learning environment (VLE) where learners can learn independently by collaboration and cooperation through high-tech social media and thus reach the satisfactory level of second language acquisition. However, there is scope for further research. More research should be done to recognize the challenges sprouted in e-learning platform associated with the radical changes in learners' and teachers' attitudes and aptitudes towards edu-tech, and thus, establish a modern e-learning platform suitable for the 'whole child' for conducting self-regulated learning (SRL) that can generate life-long learning. This study is an attempt to recognize and address the challenges of e-learning.

\subsection{Significance of the Study}

Time befitting education environment is the only demand of the digitally obsessed i-learners. A survey in the English department of Najran University, one of the universities in the Kingdom of Saudi Arabia, where the learners are digitally savvy and have the experiences of learning in both face-to-face and online platform, help the researcher gather information and insights about the online education for the language learners. It is noteworthy that the young learners in the Kingdom of Saudi Arabia whose age is between 16 to 23 are adapting to new technologies faster than expected in recent years. According to the report given by Ar Riyadh Development Authority in 2007, approximately $60 \%$ of the young population here is using internet for different purposes since 1999 when internet access became available to the public, and the percentage increased rapidly day by day and in 2015, the percentage of the student internet users reached to $97.96 \%$ (CITC, 2015). So, the demand of the time is to implement e-learning for EFL learners in higher education. The Saudi government's Ministry of Higher Education has taken the initiative to shift traditional learning to e-learning by launching many development projects to establish adequate IT infrastructure as well as content development for higher education. NCEL (National Centre for E-learning) and SANEED (the Saudi Centre for Support and Counselling) have already been established and they are supporting the university online learners and the teachers with all technological and training needs (MOHE, 2011). It is remarkable that presently most of the institutions and instructors in Saudi Arabia have changed their methods of teaching and learning with technological development (Al Augub, 2007). Introducing technology in the education sector has widened the scope for the learners and the teachers to collect more information and to establish the interaction between students and students as well as students and teachers even without time and space limits in two different models-synchronous and asynchronous that are equally important for developing communication and collaboration. To keep abreast with the current trends in education in Saudi Arabia, Najran University has recently moved towards the implementation of online learning as an alternative to traditional education. Blackboard is used LMS in this university. There is a deanship supporting all online course delivery methods. Here, the students and the instructors value the LMS as an enhancement of their learning and teaching experiences but relatively few teachers and students use these systems to the full capacity till now. AL-Augub (2007) urges the researchers to do more research on online learning in Saudi Higher Education to find out the challenges faced by Saudi learners and teachers. Therefore, this study is important to know about the attitude and aptitude of Najran university students and teachers to use online courses to get the best benefit. For this, a small number of students and teachers of the English department were selected for delivering e-learning. The survey questionnaires and interviews were set to collect information about the learning environment, provided teaching materials, the efficiency level of teachers as well as students in using e-learning tools, and also learner's psychological and social development in acceptance of e-learning. The researcher believes that the findings will show both the community of practitioners and the learning community the smooth pathway to select proper educational tools, materials, and contents adjusted with cultural context.

\subsection{Objectives of the Study}

This research aims to establish an interactive, dynamic, virtual learning platform where the language learners can happily and comfortably lead the learning process; thus, second language acquisition will be easier, faster, and more dynamic for them. Two important things have been focused on. They are:

1) E-learning challenges in consideration of learners' and teachers' efficiency in the usage of modern educational tools

2) Application of modern tech-tools for improving engagement, interaction, and communication

E-learning is becoming more and more attractive to the EFL learners and teachers but still, they are facing problems in advance use of tech-tool for education and also in effective interaction and collaboration. It is noticeable, in e-learning courses at the English department in Najran University, the second language learners 
and teachers showed their profound interest in e-learning but they could not attain the target learning outcomes. A survey was conducted mainly on three different aspects that are intertwined with each other for regulating successful learning process in the virtual classroom:

1) 21 st-century learners' and teachers' attitudes

2) Interactions and relationships between learners and teachers

3) Students' and teachers' adaptation capability with new technologies

For learning English as a second language, learners should give maximum time and effort to know the culture of the target language and the usage of it in a real-life situation. E-learning widens this scope if the learners and teachers become motivated and acquire the skills needed for governing Self-regulated Learning (SRL) successfully on e-platform. So, more and more research should be done on 21 st-century learners' and teachers' attitudes and aptitudes about online education for selecting such a supportive environment that can foster dynamic qualities of the language learners in order to enable them to regulate their own learning process. It is expected the findings of this research will make a significant contribution in the field of self-regulated e-learning for the EFL learners at the university level.

\section{Literature Review}

Krashen's theory that comprehensible input is crucial for the second language acquisition and it is the interaction that can enhance second language acquisition (Krashen, 1994) is a landmark in language acquisition theory. Obviously developing a participatory culture with interaction and negotiation provides learners with comprehensible input and output. Krashen's theory works as an incentive of e-learning with the innovation of Edu-tech-tools as VLE can provide the opportunity for ample learner-learner, learner-instructor, and leaner-content interaction flexible in accessible settings than traditional classrooms and language labs. Researchers have described VLE as a platform congenial for doing multiple tasks like sharing instructional materials, making class announcements, submitting and returning course assignments and communicating with each other and all these together form individualized learning (Nambiar, Nor, Ismail, \& Adam, 2017). However, continuous development of media and technology has brought a tremendous change in learners' behaviour and attitude as well as in learning pedagogy. Today's learners are active and they adhere to self-directed discovery. For this, they need an informal learning environment, self-regulation skills as well as the support of the instructors. That is why the education industry is found in a non-stop journey for navigating the perfect stimulus learning environment where the learners will have many options for expression and free movement. Different researches have been done on modern-day learners' behaviour, expectations, and goals. One of the researchers, Bill Sheskey (2010) in his book Curriculum 21: Essential Education for a Changing World describes the nature of the 21 st-century learners. He says, “... students entering the classroom today are much different from those who have come before. Today's students are demanding a change in the classroom because of their ability to gather information faster than any previous generation.” (p. 197)

Again, Al-Shahrani and Al-Shehri (2012) use the term 'Digital Savvy' for the young learners who are tech-lovers and always crave for the latest version of mobiles, laptops, iPods, IPads etc. For these learners, Takalani (2008) advocates e-learning as it encourages them to be self-regulated and to build self-knowledge and self-confidence. To Jasinski e-learning is "a fast transition from the conceptual to the operational". He further explores, there is no hard and fast rule for today's learning rather happily learners can learn by playing with the rules, or creating a new realm of learning conjuring with the consisting rules. Holec $(1988$, p. 8) uses the term 'autonomous' to describe these learners as well as the nature of learning. He says,

...the autonomous learner is not automatically obliged to self-direct his learning either totally or even partially. The learner will make use of his ability to do this only if he so wishes or if he is permitted to do so by the material, social and psychological constraints to which he is subjected.

Carol Ann Tomlinson also stated, "In a less complex-less human-world, teaching might simply be telling young people what's important to know. In such a setting, students will say, 'I see. Thanks'. And the whole world goes forward." (Tomlinson, 2001)

From their voices it is clear, 21st-century learners have the ability, desire and freedom; hence, the infra-structure of e-learning environment as well as the pedagogical selection works as main incentives. For this, first of all, the decision-makers should target the fundamental achievement of e-learning and this is "communication, interactivity and social cohesion" according to Brennan (2003). For attaining all these three, Intakhab (2011) hypothesizes both unidirectional and bidirectional interactions between the students and their peers and between the students and the teachers, and he considers these as successful motivating factors. It is noticeable that in 
present days for the advancement of technology, both synchronous and asynchronous modes of learning conducted through different websites, e-mail, e-chatting, streaming video have become convenient. In fact, interactive technologies and communication system improve learners' experience and widen their participation in lifelong learning, and it is virtual learning environment (VLE) where learners and teachers can have the equitable access to quality learning tools. Semens (2003) claims that variety is the fundamental need for quality learning, and media choices should be made targeting the desired learning outcomes.

However, research on quality e-learning has emerged recently in the 19th century and systematic research on teachers' as well as the designers' professional development in using e-learning tools, making contents, and creating e-infrastructure for bringing the learners' emotional, social, physical and academic efficiency has also developed. In fact, instructors' and students' competency in the use of e-tools for education is the requisite of E-learning (Blinco et al., 2004). For this, Salmon (2004) urges for training in order to make all the members of education industry competent enough to face the challenges in new pedagogical journey, from traditional to e-learning because technological, organizational and pedagogical challenges hinder the successful implementation of e-learning (Tarns, 2011). It is an undeniable fact that most of the universities both in developed and developing countries are facing difficulties in implementation of effective e-learning and the result is the call for blended learning (Balci \& Soran, 2009). So, more research is needed to investigate the barriers of the quality education delivered in an online platform. Here Skelton's (2007) statement is noteworthy, 'no educational institution should be forced by the trends and rise of internet activities to jump on board regardless of the cost to academic quality and sense of community' (p. 147). After reviewing other researches, the researcher feels an urgency of conducting a study on the experiences of the learners and the teachers of the department of English (Girls' section) of Najran University, and the result will open the door of further research.

\section{Methods}

\subsection{Participants}

This research is carried out through a survey among the learners and the instructors of the English department of Najran University in the Kingdom of Saudi Arabia. A set of a structured questionnaire with open-ended questions as well as the interviews are administered to collect data from 50 students randomly selected from different levels and 30 instructors who have e-language learning and teaching experiences.

\subsection{Data Collection}

Three sets of questionnaires were prepared for measuring learners' motivation level in this new learning atmosphere, learners' confidence level in using technology in education, and also instructors' attitudes towards technology, pedagogy and content. A 2-point Likert Scale ranging from 'Agree' to 'Disagree' was used in this study. Some items on the questionnaire were used for obtaining qualitative and quantitative data adopted by Collin's and Virginie's E-learning in Europe (Virginie \& Colin, 2006) to gather information on participants' experience and expectation on e-learning. The questionnaires are distributed with clear instruction and explanation. In addition, for the interview session, the questions were designed strategically to have the voice of the participants to collect additional information about e-learning challenges, and thus the researcher feels comfortable to collect comparable data. The adopted method makes the researcher more confident in replicating the most appropriate design of e-learning that can easily help attain the target learning outcomes, and in this respect, the researcher becomes highly motivated by Bogdan and Biklen (1998).

\subsection{Data Analysis}

Basic descriptive statistics seemed useful to explain the data collected from a number of learners and teachers through interview and questionnaire. Moreover, to justify the authenticity of the result of the survey various documents like university reports, strategic plans, university policies, Ministry of Education's document and relevant journal of earlier researches are analyzed by the researcher herself adjusting with her own experience. Obviously, the steps taken for establishing the authenticity of the survey result will open the door of future research for the successful implementation of e-learning in higher education.

\section{Result and Discussion}

The survey data of the study are presented in three separate sections and the analysis of the result gets the full shape with a connection of the experiences of the learners and the teachers collected by the interview session.

\subsection{EFL Learners' Attitudes Towards E-Learning}

This section measures and presents the data of the attitudinal changes of 21 st-century language learners. It gives a clear picture of their interest in the usage of technology in learning English as well as their interest in 
self-learning. No one can deny that motivation is the most important thing in the field of e-foreign language learning. So, the target of this section is to find out the answer to the question-To what extent are the learners facilitated to use their skills at digital collaborative self-regulated learning? For this, a questionnaire was designed to find out their interest in work with their peers and instructors in VLE. The questions mainly targeted the interest of the learners in communication, collaboration, and interaction by opening discussion forums, blogs, and other social networking sites like Whatsapp, Twitter and so on. Some questions were also brought to measure 21st-century tech-savvy learners' attitude towards self-regulated e-learning. The chart below reflects the dynamic characteristics of EFL learners in this digital age:

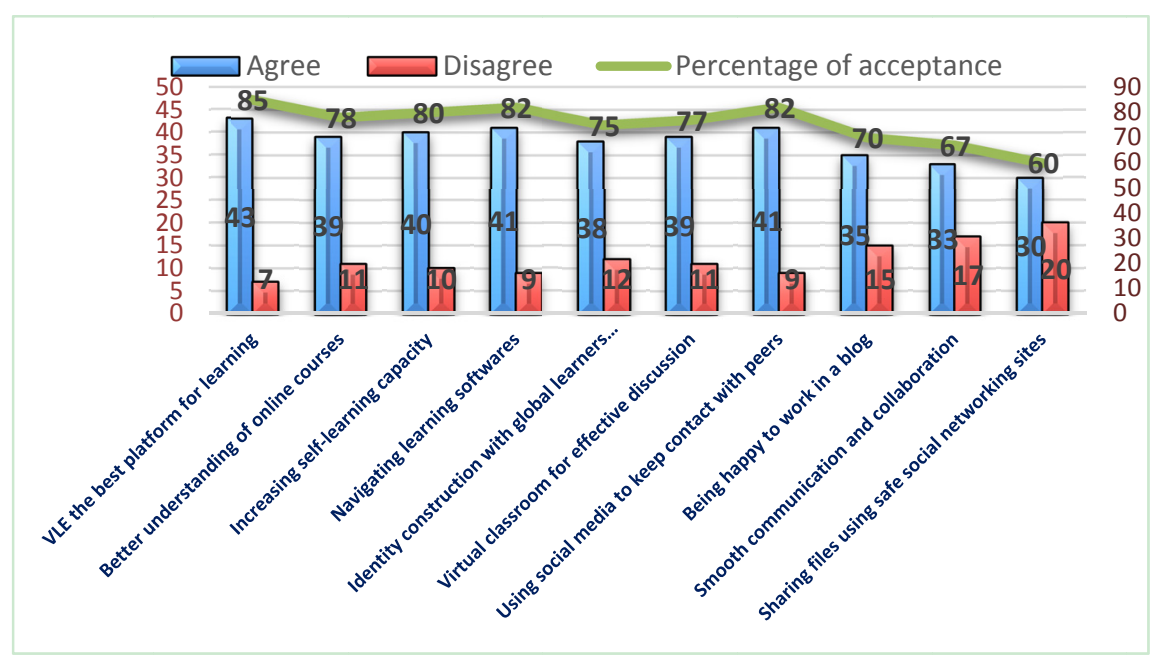

Figure 1. EFL learners' attitude towards E-learning

From this study, we get the idea that $90 \%$ of today's language learners are very happy to enter VLE instead of going to a traditional classroom. The percentage of their acceptance of e-learning is high. Among them $78 \%$ claims, e-learning makes the course more understandable as the learners can repeat the same lecture whenever they need and they can use the other learning resources. Today's learners are dynamic; they like to learn by themselves and so, $80 \%$ show their interest in self-regulated e-learning. Again, youth today are very curious to know about the unknown. As a result, $82 \%$ of them are always found busy at browsing different learning software for collecting more information about the courses. Again, $75 \%$ of learners believe that virtual classroom brings the learners from different corners of the world in one platform and thus create the unique feelings of oneness with global learners' community. In this platform, most of the learners who learn English as the second language happily engage themselves in discussion with others especially with the native speakers and $77 \%$ students found this discussion effective to improve their listening, speaking, reading, and writing skills. It clearly indicates that the learners are very smart to accept learning with a smartphone. They feel, e-learning with free movement improves their knowledge, understanding, and also increases the opportunity of interaction with native and non-native speakers that help them enrich their vocabularies and their correct use in sentences in different contexts. However, the low percentage is found in collaboration and interaction. From the data, it is noticeable that the learners are more active in ensuring their presence in social media platform than in creating blog entries for sharing files, ideas, or doing the assignment. The figure shows the percentage of the learners who like to keep contact with peers through social media especially Facebook, Whatsapp is very high, $82 \%$, but their participation in blogs for completing an assignment is moderate, only $70 \%$. The cause is figured out by $67 \%$ of learners' complain about the difficulty of the use of tech-tools for communication and collaboration. Furthermore, a smaller percentage $(60 \%)$ is found interested in sharing files through social networking sites as they are afraid of their files being copied or attacked by viruses. So, the highly concerning matter here is the lowest level of interest in collaboration and interaction that is the precondition of self-regulated learning for developing second language learning skills.

\subsection{EFL Learners' Efficiency in the Use of Technology in Education}

It is true that the more the language learners will improve their technological aptitude and efficiency, the more they will be involved in different activities in different learning platform as their knowledge and skills about using tech tools will keep them free from tech-anxiety. From the statistics published in 2014 EDUCAUSE report 
that around $86 \%$ of the young generation are 'Tech- Savvy' and it is increasing day by day. The following chart shows how many of them are skilled at using technology for education:

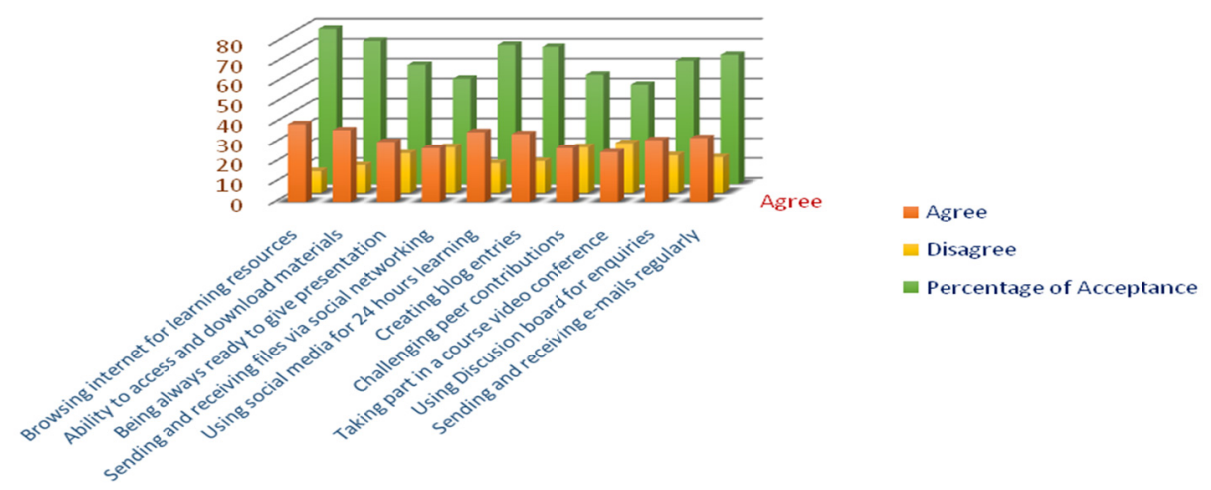

Figure 2. Learners' efficiency in the use of technology in education

From the responses to the questionnaire designed for e-efficiency test of the EFL learners, it becomes clear that the youths today are generally technologically confident but not necessarily comfortable with their institution's technology services and applications. From the graph, we get the idea that the learners' readiness to collect information using a smartphone is noticeably high. $78 \%$ of students almost everyday surf internet and $72 \%$ of them can successfully download the materials needed to make the course more understandable. It reflects the behavioural changes of the natives of this tech-oriented global village. But at the same time, many of them do not have a very good idea about how to validate, synthesize and leverage information. That is why only $60 \%$ of the respondents are ready to give presentation; around $53 \%$ of them show their competency in sharing activities, files and ideas via social media; whereas, $70 \%$ remain active online social media platform maximum hours in a day and get the chances of developing their writing and speaking skill with informal approach. However, the students' percentage in creating blog entries is not satisfactory; it is $69 \%$. They are found hesitant in exchanging their opinions in blogs. Only 55\% like to post discussion comments. But the advantages the EFL bloggers get are "the choice of more appropriate language on the part of the learners, the addition of new perspectives to the learners' thoughts, and the motivational aspect of realizing that one's voice echoes in distant parts of the globe and is heard by others" (Arena, 2008, p. 4). Again, the percentage is significantly low, just 50\%, in video conferencing as well as in attending virtual classes that is essential in e-learning. Yamagata-Lynch advocates synchronous session as an effective instrument of creating a high level of motivation for tech-engagement activities in the real-time presence of teachers and students on e-platform (Yamagata-Lynch, 2014). It is noticeable that the fascination towards blogs, discussion board, and other social media for communication is higher but without attaining the skills only their interest cannot bring a satisfactory level of learners' interaction and collaboration. Therefore, their acceptance of the use of Discussion board and e-mail is moderate.

\subsection{EFL Teachers' Attitudes and Aptitudes Towards E-Language Learning}

In e-learning, teachers play the role of 'mentor', 'coach', 'facilitator', and 'a transmitter of knowledge'. Their enthusiasm along with skills required for adapting to Edu-tech tools can ensure all the learners' engagement in a safe collaborative environment. This section will help to investigate the challenges that the instructors are facing to create a smooth learning path for digital learners using the latest technology. A three-part questionnaire was distributed among the teachers to measure i) their attitudes towards e-learning, ii) their tech-use skills, and iii) their aptitudes in communication and collaboration in e-platform.

\subsubsection{Teachers' Interest}

The first part of the study shows, $85 \%$ of the teachers are highly interested in delivering courses online as they consider VLE the only platform that can bring effective interactive engagement among the students and the teachers. For creating the best twenty-four hours self-regulated e-learning engagement $80 \%$ of them strongly support the positive effect of using discussion board and forum for regulating independent learning with the 
direct contact of the peers and the instructors. On the other hand, $83 \%$ of teachers feel that video conferencing is more enjoyable and productive. It is a substitute for face-to-face learning. It provides students with such a live learning paradigm where language learners can easily develop listening and speaking skills in real-life experience. Again, the level of interest is not that much high in the use of e-mail (70\%), blogs (69\%), and recorded lectures $(73 \%)$ to increase the students' learning hours, and also the engagement with the teachers though $81 \%$ of them accept the idea that social media is useful for interaction, communication, and collaboration. The figure below shows the teachers' interest in the use of e-learning tools for motivating learners' self-regulated e-learning:

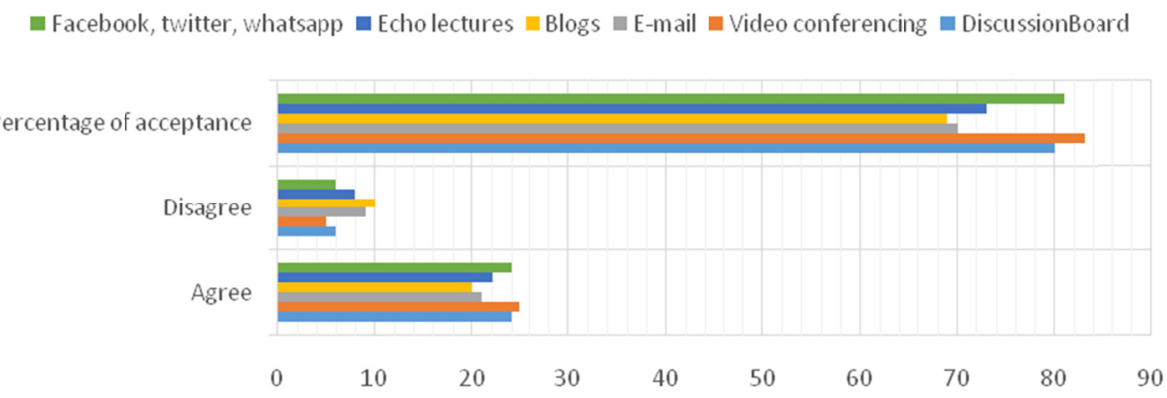

Figure 3. Instructors' positive attitude towards e-learning tools for interaction

\subsubsection{Teachers' Experience in the Usage of Composition Tools}

The second part identifies teachers' efficiency at the use of composition tools for instructional design as well as creating e-learning contents. The following bar graph conveys a very clear idea about their skills in six composition tools:

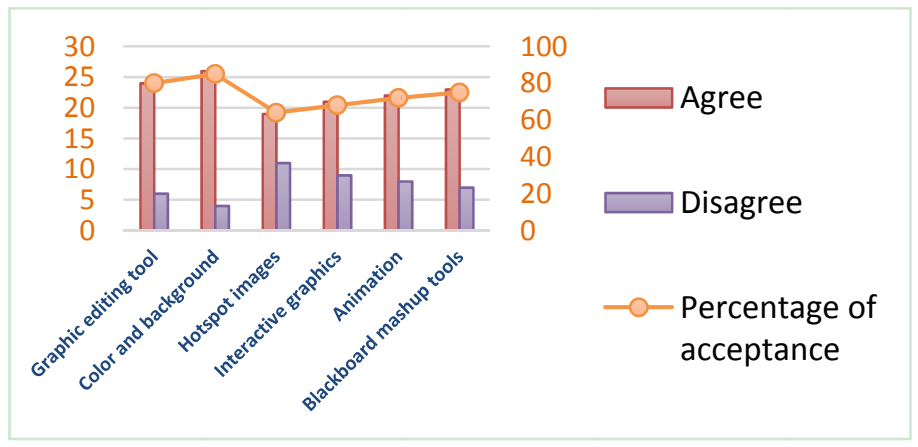

Figure 4. Instructors' aptitude towards composition tools

Obviously, instructional design affects learners' motivation as well as learning. In this respect, $80 \%$ teachers are found highly skilled in sorting and organizing the information using graphics editing tool, and $85 \%$ in assimilating the message from colour and background in PowerPoint presentation (PPP). Again, the percentage is moderate that have the skill of the use of the blackboard mashup tool to fuse disparate data sources in a single environment, and also the use of animations in PPP without detracting the message intended to deliver. To $75 \%$ teachers, blackboard mashup tools are easy to use, and $72 \%$ like to make PPP attractive to the learners with animations as they think that animations in PPP give the learners real-life experience where effective and efficient second language learning happens. However, $68 \%$ teachers have satisfactory knowledge about how to use interactive graphics, and only $64 \%$ show their skill in the use of hotspot images effectively for instructional design that brings the negative impact upon self-regulated e-learning. It is true that the efficient users of graphic editing tools can present such situated learning where learners develop their knowledge, thinking power, and creativity that are the characteristics of a dynamic person. 


\subsubsection{Teachers' Skill at Culturing Participatory Culture}

Finally, the study with the third part of the questionnaire reveals the course instructors' experience in creating more engagement of students in a collaborative environment:

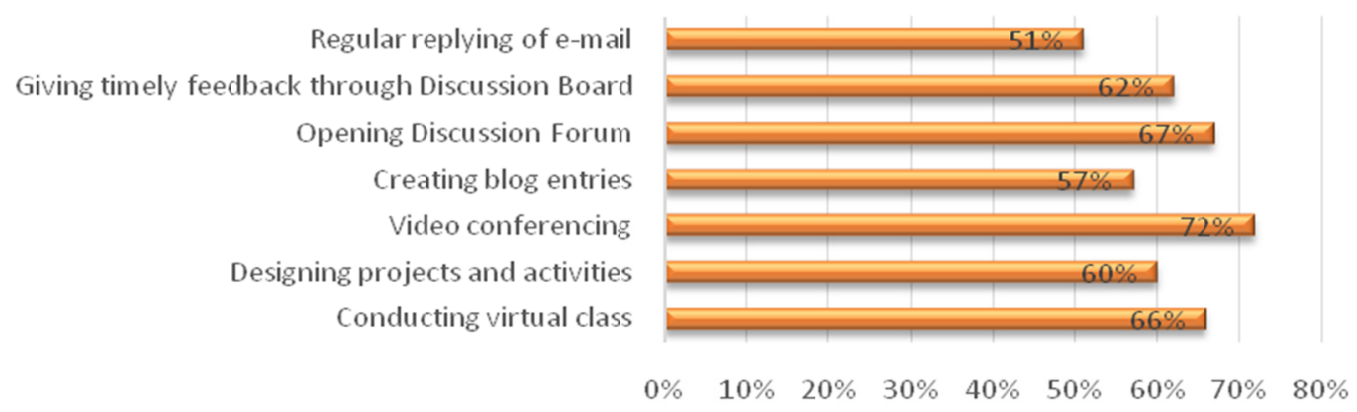

Figure 5. Instructors' interest in improving learners' collaboration and engagement

It is true, the more the teachers use e-learning collaborative and interactive tools efficiently for creating different learning experiences for the students, the more the students find themselves engaged in the completion of a collaborative project. The study shows only $66 \%$ of teachers efficiently use the latest virtual classroom software to make e-learning experience effective and engaging. Again, only $60 \%$ of teachers successfully design projects or activities for developing collaboration. As a result, the uploaded materials and the instruction could not make the learners active rather keep them passive. However, instructors' interest in video conferencing is respectively high (72\%). This also cannot bring a satisfactory result in learners' motivation. For the poor knowledge about instructional design, teachers were unable to arouse learners' confidence to reach the target of self-regulated learning. On the other hand, the percentage of the instructors in using WebCT or Blackboard tools for creating blog entries is low, $57 \%$; whereas, teachers felt more comfortable with discussion forum for answering enquiries sent by the learners though the percentage of the users of the discussion board was not that much high, just $67 \%$. The surprisingly noticeable factor is the low percentage of interaction between learners and teachers for regular replying of e-mail and giving timely feedback, $51 \%$ and $62 \%$. It seems that the instructors failed to give the students timely feedback, to reply their mails regularly, and to answer their messages immediately; as a result, motivation regulation was being slowed down and the aim of creating interactive and integrative learning environment did not get a full shape.

The analysis of the survey results in three different sections highlights three areas: interest in e-learning, tech-tool usage skills, and interaction and collaboration that significantly lead to the emerging idea of participatory culture for regulating independent learning that is essential to become a successful EFL learner. These three are identified as the most important factors that influence language learning of the dynamic EFL learners.

According to the survey result, both second language learners and instructors are highly interested in today's dynamic concept of learning and teaching that is based on multimedia, but their skill, as well as knowledge level on the use of tech-tools in education, is not that much high, and the main noticeable factor is the low level of collaboration and interaction that is considered the main obstruction for the learners to accept e-learning paradigm without any hesitation. It is an undeniable fact that all these three-motivation, collaboration or interaction, and e-skills are intertwined with one another for bringing a dramatic change in English as Foreign Language Learning and Teaching Pedagogy (EFLLTP).

The survey result suggests that it is important to find out the causes behind the dissatisfactory level of collaboration and interaction as these two are regarded as the most important in the emerging pedagogical approach of participatory culture since these two significantly generate knowledge and creativity of the learners. Some reasons are pointed out through interviews taken of the participants from their experiences.

In the interview session, most of the students appreciated e-learning as perfect for them because it created for them such a platform where they could learn without being bound to a particular time and place. In the 
questionnaire, many students felt online education has made the materials more understandable and less boring; whereas, they demand more "Elluminate Live Session" so they can discover their identities as a student connected with their peers under the guidance of an instructor in e-classroom though some participants complained 'technology difficulties' that sometimes made them feel isolated from others as well as unable to access the platform and videos:

"Sometimes I needed to wait for learning a lesson until I went back home and opened my laptop or desktop with a high-speed internet connection. So, I passed my time with worries about missing some lectures or submitting my assignment on time."

So, both synchronous and asynchronous modes are necessary to attain a satisfactory level of learning outcomes. In synchronous learning, learners get the opportunities of direct interaction with the peers and instructors as well as immediate feedback and assistance that remove their worries and tension of not getting a clear idea about the courses; the nature of the course and also the expectation of the institution. On the other hand, asynchronous mode leads the learners to self-regulated learning where learners can enter various learning kingdoms to collect information and thus attain creativity and deep understanding and learning. Autonomous language learners face cognitive and metacognitive challenges. They need to be highly skilled at time management, goal setting, self-monitoring, self-evaluation, and effort-regulation. Besides, teachers should have "psycho pedagogic knowledge" that can make them skilled at applying those strategies and techniques necessary to continue their self-directed e-language learning process in a comfortable, friendly environment; therefore, in interview session, only those teachers were appreciated who successfully could apply "motivating strategies" and thus involved them in performing best intellectual activities.

Obviously, in e-language learning, motivation is the most important thing to engage all the students in learning. In one class, some are found very active but some very shy and have poor linguistic skills, and so can't feel comfortable in using discussion board or blogs for communication and collaboration with their fellows and instructors. For example, one student expressed her desire in the interview saying,

"If blackboard had a chat option like Facebook, I would have stayed logged in and I could do my work and chat with my fellow mates as here informal language works well."

Attaining linguistic skills is important for the students but language learners become proficient by using the language not just by learning about the language. In the survey result, we found the teachers unable to motivate the learners in interaction and communication through social media platform smoothly and happily. Here, it is important to know that only a digital literacy teacher can integrate real-life target language situation to enhance the motivation for the use of both formal and informal language on a different social media platform and thus can promote learners' language acquisition. According to Krashen, to learn English as a second language, learners need not give any conscious effort rather they should more and more expose themselves to the target language.

Again, about collaboration another participant said,

"I feel frustrated when I work with people who are more competent than me and I become more and more aware of not being at their level."

Such type of speech is really frustrating because second language learners who lack confidence and have low tech-skills retard from others. For acquiring a high level of proficiency in English, learners' engagement is essential. Clear teaching instruction methods can be helpful to attain group collaboration. Edu-tech tools provide more chances for the instructors to keep the learners engaged in multi-tasks if they are used in creative ways.

Some other students also complained against assessment style saying,

"Assessment focuses only on the final product, and individual participation was not taken into account.

There are always people that take advantage of this."

The voice reflects the chance of losing interest in developing a participatory culture for the limitation of collaborative assessment. To avoid this, before assigning group work, a teacher should formulate a clear assessment method where individual learners' contribution and their level of understanding will be apparent with the final achievement of the group.

Again, some expressed their dissatisfaction at knowledge sharing activities because of not having sufficient technical skills and the proper guidance of their instructors as well as timely feedback. They insisted on the continuous relationship with teachers and they requested the availability of a virtual teacher round the clock to communicate with. It is suggested, web conferencing can work best for constant monitoring of the text chat 
panel so that any of the learner's questions cannot be ignored. Thus, under a vigilant teacher, the learners' engagement in group activities will create more opportunities for them to learn how to use sentences, words, grammar, and spelling correctly and appropriately.

Obviously, to solve all the problems mentioned by the learners, instructors' initiative is urgently needed. The instructors who participated in interview session valued 'chat' as an important tool to promote interaction; besides, they admitted that for the lack of time and easy-tech service, they were unable to make participatory platform 'more dynamic', 'more open schedule'. They feel, their big challenge is to increase the motivation level of the learners by giving them more time and a more interactive engaging classroom experience through the blackboard and also through social media. They also demand more and more training sessions for all the people engaged in learning, teaching, and designing the course contents.

\section{Suggested Steps}

After analyzing the present scenario of online education in the English department, Girls' section of Najran University in the Kingdom of Saudi Arabia, it becomes clear that most e-language learning challenges are related to tech-skills, time management and technology difficulties as well as the lack of effective communication and virtual collaboration and competencies. For launching effective self-regulated e-language learning program the policymaker and the course designers or instructors should be dedicated enough to design such a virtual learning platform where all the learners can happily engage themselves in different creative activities assigned as group work with full satisfaction, and they will easily develop linguistic skills through active participation in the e-learning platform.

Here are some recommendations that can be followed to overcome e-learning challenges as well as to establish a smooth, comfortable online education platform for the dynamic second language learners:

1) In today's digital climate, it's a necessity to develop a responsive e-learning course by making it multiplatform-friendly to cater for learners moving between devices like tablet, smartphone, laptop, and so on. As mobile device usage is on the rise, advance time-befitting m-learning websites building like cloud computing AWS (Amazon Web Service) and GCS (Google Cloud Service) is an urgent need to create portable and knowledge packed mobile learning experiences for the learners.

2) For promoting e-language learning both synchronous and asynchronous delivery should be ensured so that the learners can attend the live virtual course and at the same time can complete course works offline, and thus, all of them equally can be able to be delved into a specific subject or skill set. On the one hand, synchronous mode leads the learners to conscious language learning where they get immediate feedback and practise reading and writing with error analysis. On the other hand, asynchronous mode creates more opportunities for unconscious language learning that lead the learners to know about the formulation of syntactically and semantically correct sentences.

3) Synchronous chat like Whatsapp, Facebook generates a lot of interaction but is tiring and time consuming for the teacher. To make it faster and more interesting, chat-bot or web-bot can be the perfect app to provide the right and in time replies. Only more effort should be given to make a chat-bot response human-like and to develop web-bot reply to students' enquiries and FAQs in a more vibrant and relaxed way.

4) Asynchronous communication with discussion board, e-mail is definitely useful to answer inquiries and doubts; however, answering all emails on a daily basis is not only inefficient but also human laborious. Automated reply machine along with Artificial Intelligence (AI) can be added to give the learners an immediate solution with effective and real-life experience.

5) In this fast-paced world of e-learning, course contents should be updated quickly to bring the adjustment with the advent of new tech education tools to make the course effective and time-befitting.

6) To engage a group of students through digital means is really a challenging task. It requires the commitment and noble contribution of the learners and the instructors. So, instructors should incorporate more activities that are more interactive and require the students to brainstorm and research a topic in both. Moreover, to get the most out of the online learning experience, they can redirect students to additional web resources.

7) Holographic display is considered the best facilitator of collaborative learning. For this, a virtual campus can launch different projects like Scholar Project to bring 3D to 7D visualization where students can feel their physical presence and oneness among the global generation.

8) Creating different blogs, forum, discussion board and other social platforms like twitter, Whatsapp, Facebook is an urgent need for more interactions among the learners to remove instructional as well as identity 
construction problem.

In conclusion, in the present technology-driven society, no learning can be effective and life-long for the tech-generation without a Dynamic Learning Environment (DLE). Although most of the universities are conducting non-stop experiment on the new version of Blackboard with upgraded tools, they are not getting satisfactory result. Now it is clear, only the Blackboard without navigating other profit LMS and pedagogies cannot make the effort successful to reach the goal. So, for getting the best benefit from e-learning, more importance should be given on the comfort with the hardware and the mastery of the software program. DLE is suitable for those learners who are very smart to learn or engage with the materials and join different groups for collaboration and interaction using digital tools and resources without any hesitation. Finally, a successful e-learning project will ensure proper tools with a pedagogical and instructional model as well as skilled instructors with great commitment to building a knowledge society with dynamic learners. Most importantly, learners are one of the most important stake-holders in an e-learning project and so, designing and developing an e-language course with them in mind can lead the project to the target.

The voice is here to add a new version of e-tech apps and software and also skill development project to make self-regulated e-learning more interesting and comfortable to the digital EFL learners and the teachers. Obviously, further research will explore in-depth knowledge of implementation of the ideas mentioned in this paper and thus will open a smooth path for the education industry to make this tech-oriented language learning successful for the tech-savvy learners. McLuhan declares the same message "We shape our tools, and thereafter our tools shape us" (McLuhan, 1995, p. ix)

\section{Declaration}

I declare that this research article is my own and has been generated by me as the result of my own experience of teaching in both face-to-face and e-platform and also of the survey conducted with questionnaires and interviews among the undergraduate students of different levels and the teachers who share their experiences and provide their valuable suggestions. The data that support the findings of this study are accurate and available on request from the author. I would also like to confirm that there are no known conflicts of interest associated with this publication and there has been no significant financial support for this work that could have influenced its outcome.

\section{References}

Al Shahrani, K., \& Al-Shehri, S. (2012). Conceptions and responses to e-learning: The case of EFL teachers and students in a Saudi Arabian University. Monash University Linguistic Papers, 8 (No1ISSN 1327-9130), 21 31.

Al-Adwan, A., Al-Adwan, A., \& Smedley, J. (2013). Exploring students' acceptance of e-learning using Technology Acceptance Model in Jordanian universities. International Journal of Education and Development using Information and Communication Technology, 9(2), 4-18.

Al-Augub, A. M. (2007). Benefits, barriers and attitudes of Saudi female faculty and students towards online learning in higher education. Doctoral dissertation. Available from ProQuest Dissertations and Theses database. (UMI No. 3258686)

Al-Mousa, A., \& Al- Mubarak, A. (2005). E-Learning, Basics and Applications, Riyadh, KSA, Data Network.

Al-Sharhani, J. (2000). Education and the satellite: Possibilities for Saudi Arabia. International Journal of Instructional Media, 27, 51-57.

Alharbi, A. (2013). E-learning in the KSA: A Taxonomy of Learning Methods in Saudi Arabia. Auckland University of New Zealand, PGR15 deposit in AUT library.

Alvarez, I., Guasch, T., \& Espasa, A. (2009). University Teacher Roles and Competencies in Online Learning Environments: A Theoretical Analysis of Teaching and Learning Practices. European Journal of Teacher Education, 32(3), 321-336. https://doi.org/10.1080/02619760802624104

Arena, C. (2008). Blogging in the language classroom: It does not simply happen. TSEL-EJ. Teaching English as a Second or Foreign Language, 1, 4. Retrieved from

http://www.tesl-ej.org/wordpress/past-issues/volume11/ej44/ej44a3/

ArRiyadh Development Authority. (n.d.). The population in ArRiyadh City. Retrieved from http://www.ada.gov.sa/Researches/index.as [Google Scholar]

Balci, M., \& Soran, H. (2009). Student's opinions on blended learning. Turkish Online Journal of Distance 
Education-TOJDE, 10 .

Blinco, K., Mason, J., McLean, N., \&Wilson, S. (2004). Trends and issues in e-learning infrastructure development: A White Paper for alt-i-lab. Prepared on behalf of DEST (Australia) and JISC-CETIS (UK).

Bodgan, R. C., \& Biklen, S. K. (1998). Qualitative research for education: An introduction to theory and methods. Boston: Allyn and Bacon.

Brennan, R. (2003). One Size Doesn't Fit All- Pedagogy in the online environment. Adelaide: National Centre for Vocational Education Research, 1. Retrieved October 17, 2003, from http://www.ncver.edu.au/publications/965.html.

Chen, B., \& Bauer, S. (2015). Students'Mobile Learning Practices in Higher Education: A Multi-Year Study.

Chen, C.-M, (2007). Intelligent web-based learning system with personalized learning path guidance. Computers and Education, 1-28. https://doi.org/10.1016/j.compedu.2007.08.004

CITC Riyadh. (2007). Communications and Information Technology Commission Report on number of internet users in Saudi Arabia [Google Scholar].

CITC Riyadh. (2015). Individuals Report ICT Survey Results of internet users in Saudi Arabia [Google Scholar]

Elaine, I. A., \& Jeff, S. (2008). Staying the course: Online education in the United States, 2008. Needham, Mass.: Sloan-C, and retrieved February 17, 2009 from http:/www.sloan-c.org/publications/survey/index.asp,

Florentino, B. E. (2004). A training proposal for e-learning teacher: Dpto.CC. Education. Avda Elvas s/n. University of Extremadura, Badajoz, Spain.

Garrison, D. R., Cleveland-Innes, M., \& Fung, T. (2004). Student role adjustment in online communities of inquiry: Model and instrument validation. Journal of Asynchronous Learning Networks, 8(2), 61-74. https://doi.org/10.24059/olj.v8i2.1828

Garrison, R. (2000). Theoretical challenges for distance education in the 21st century: A shift from structural to transactional issues. International Review of Research in Open and Distance Learning, 1(1). Retrieved from http://www.irrodl.org/content/v1.1/randy.pdf]. https://doi.org/10.19173/irrodl.v1i1.2

Green, J. S., \& Eves, C. G. (2001). Online teaching using an electronic forum in distance Education. New Zealand Journal of Applied Computing and Information Technology, 5(1), 41-42.

Hargreaves, A. (2003). Teaching in the Knowledge Society: Education in the Age of Insecurity. New York, NY: Teachers College Press.

Holec, H. (1981). Autonomy and Foreign Language Learning. Oxford: Pergamon.

Holec, H. (1988). Autonomy-self-directed learning: Present fields of application. Strasbourg: Council of Europe.

Huang, G. J., Yin, P.-Y., \& Wang, T.-T. (2007). An enhanced generic approach to optimizing auto-reply accuracy of an e-learning system. Computers and Education, 51(1), 337-353.

https://doi.org/10.1016/j.compedu.2007.05.014

Iqbal, M. M. (2014). Automated Web-Bot Implementation Using Machine Learning Techniques in eLearning Paradigm. Journal of Applied Environmental and Biological Sciences, Text Road Pub.

Krashen, S. (1994). The input hypothesis and its rivals. In N. Ellis (Ed.), Implicit and explicit learning of languages (pp. 45-77). London: Academic Press.

Ministry of Higher Education (MOHE). (2011). The Current Status of Higher Education in the Kingdom of Saudi Arabia. Retrieved from http:/www.mohe.gov.sa/en/Ministry/General-administration-for-Public-relations/BooksList/stat7eng.pdf

Nambiar, R., Nor, N. M., Ismail, K., \& Adam, S. (2017). New Learning Spaces and Transformations in Teacher Pedagogy and Student Learning Behavior in the Language Learning Classroom. 3L: Language, Linguistics, Literature, 23(4), 29-40. https://doi.org/10.17576/3L-2017-2304-03

Rawda A. O., \& Shareefeh, G. A. (2016). E-Learning Competencies Practice Level among Faculty Members at Najran University. Saudi Journal of Educational Technology Research, 2(1).

Saleh, B. (2005). E-Learning and Instruction Design: Partnership for Quality. A research Paper Presented for the 10th Conference of Egyptian Society for E-Learning Technology and the Requirement of Comprehensive Quality, Cairo. 
Salmon, G. (2004). E-moderating: The key to teaching and learning online (2nd ed.). Oxford shire: Taylor \& Francis Books Ltd. https://doi.org/10.4324/9780203465424

Saudi Ministry of Communication and Information Technology. (2005). The Annual Report for the National Communications and Information Technology Plan. Riyadh, KSA.

Sheskey, B. (2010). Creating Learning Connections with Today's Tech-Savvy Student. In H. J. Heidi (Ed.), Curriculum 21: Essential Education for a Changing World (pp. 195-209). Alexandria, Verginia, USA: ASCD.

Skelton, D. J. E. (n.d.). An Investigation into the Learning Environments of Blended Delivery (e-learning and classroom) in a Tertiary Environment. Science and Mathematics Education Centre, Curtin University of Technology.

Takalani, T. (2008). Barriers to e-learning amongst postgraduate black students in higher education in South Africa. Thesis presented in partial fulfilment of the requirements for the degree of Master of Philosophy (Information \& Knowledge Management), Stellenbosch University, Stellenbosch.

Tarus, J. (2011). Adoption of e-learning to support teaching and learning in Moi University. Thesis presented in partial fulfilment of the requirements for the degree of Master of Philosophy (Information Technology), Moi University.

Timothy, B. (2006). Agent of change: Blackboard CEO Michael Chasen erases the old way of learning. Washington Smart CEO, May, 44-53 Retrieved October 1, 2008, from http://www.smartceo.com/files/DCEO.05.06.pdf

Tomlinson, C. A. (2001). How to differentiate instruction in mixed-ability classrooms (2nd ed.). Alexandria, VA: ASCD.

Yamagata-Lynch, L. C. (2014). Blending online asynchronous and synchronous learning. The International Review of Research in Open and Distributed Learning, 15(2). https://doi.org/10.19173/irrodl.v15i2.1778

\section{Appendix A}

\section{Questionnaire designed to know about the EFL learners' e-learning experiences:}

Table 1. EFL learners' attitude towards E-learning

\begin{tabular}{lll}
\hline No. & Statement & A \\
\hline 1. & The virtual classroom provides me with a better opportunity for learning. \\
2. & E-learning helps me develop my understanding of the courses more effectively. \\
3. & E-learning creates various learning routes where I myself can easily solve my problems in studies. \\
4. & Various learning software stimulates my interest and knowledge about second language learning. \\
5. & Being an online language learner, I feel a part of the global community of digital learners. \\
6. & The virtual classroom provides me with a better opportunity for effective discussion. \\
7. & Chat tools in social media like twitter, Whatsapp, Facebook give me the chance of developing \\
& speaking, reading, and writing skills. \\
8. & Doing work in a blogging platform is enjoyable and worthwhile. \\
9. & E-learning tools for communication and collaboration are user- friendly. \\
10. & I always remain concerned about privacy and miscommunication while sharing files, information, and \\
\hline
\end{tabular}

Table 2. Learners' efficiency in the use of technology in online education

\begin{tabular}{lll}
\hline No. & Statement & A \\
\hline 1. & I can download files and save them in different formats in a folder. \\
2. & The discussion board is easy to use for sending inquiries and sharing ideas with peers. \\
3. & I can use video conferencing. \\
4. & Navigating learning software for more learning never makes me confused. \\
5. & I can use composition software to validate, synthesize, and leverage information in the presentation. \\
6. & I know how to use tools to protect files from viruses while sharing them via social networking. \\
7. & I found it difficult to comment on the posts of my peers in blogs. \\
8. & I know how to create blog entry using blackboard tools or editors. \\
9. & I keep myself engaged with my peers through Whatsapp and twitter for active participation in \\
\hline
\end{tabular}


learning.

10. I am always active in sending and receiving e-mails for regular contact with my peers and teachers.

\section{Appendix B}

\section{Questionnaire designed to know about the EFL teachers' e-learning experiences.}

Table 1. Instructors' attitude towards e-learning

\begin{tabular}{lll}
\hline No. & Statement & A \\
\hline 1. & To me, VLE is the best platform for teaching English as a Second Language. \\
2. & Discussion board and forum open the route of self-regulated learning. \\
3. & Video conferencing develops communication and collaboration. \\
& Recorded lectures uploaded on the blackboard accelerate all-time learning. \\
4. & Sending and receiving e-mails regularly work as an incentive for learners' knowledge development. \\
5. & Creating a blog seems effective for increasing students' collaborative engagement. \\
6. & Recorded lectures uploaded on the blackboard accelerate all-time learning. \\
7. & I feel social media is useful for interaction and collaboration. \\
\hline
\end{tabular}

Table 2. Instructors' efficiency level in creating e-learning contents

\begin{tabular}{lll}
\hline No. & Statement & A \\
\hline 1. & I use Blackboard Mashup tool to fuse disparate data sources on single environment. \\
2. & I always use graphic editing tool for sorting and organizing information. \\
3. & I can easily add interactive graphics in PPP to awaken students' creativity. \\
4. & Creating Hotspot images is quite easy by using Blackboard's HTML. \\
5. & I always use animations in a PowerPoint presentation and they never detract the message intended to \\
& deliver. \\
6. & I know how to use colour and background in a PowerPoint presentation to depict the message of the \\
&
\end{tabular}

Table 3. Instructors' aptitudes towards communication and collaboration tools

\begin{tabular}{lll}
\hline No. & Statement & A \\
\hline 1. & Checking and replying e-mails regularly were tiring and time-consuming. \\
2. & I like to give feedback to my students through discussion board and e-mail. \\
3. & I am happy to keep the Discussion Board opened for my students for file sharing and texts \\
& communicating.
\end{tabular}

\section{Copyrights}

Copyright for this article is retained by the author, with first publication rights granted to the journal.

This is an open-access article distributed under the terms and conditions of the Creative Commons Attribution license (http://creativecommons.org/licenses/by/4.0/). 